\title{
The Effect of $\boldsymbol{\gamma}$-Radiations on Dielectric Properties of Composite Materials $\mathrm{PE}+\mathrm{x}$ vol\% $\mathrm{TlGaSe}_{2}$
}

\author{
E. M. Gojayev, A. G. Hasanova \\ Azerbaijan Technical University, Baku, Azerbaijan \\ Email: geldar-04@mail.ru
}

Received 31 August 2015; accepted 10 October 2015; published 13 October 2015

Copyright (C) 2015 by authors and Scientific Research Publishing Inc.

This work is licensed under the Creative Commons Attribution International License (CC BY). http://creativecommons.org/licenses/by/4.0/

\section{c) (i) Open Access}

\begin{abstract}
The purpose of the paper is to study the effect of gamma irradiation on the temperature dependence of the dielectric constant $(\varepsilon)$ and dielectric loss $(\tan \delta)$ of composite materials $P E+x$ vol\% $(0 \leq x \leq 10)$. Measurements are carried out with an alternating current at a frequency of $1 \mathrm{kHz}$ using the measuring bridge E-20. Measurements are carried out at temperature range $300-450 \mathrm{~K}$, irradiated at doses of 50, 100 and $150 \mathrm{kGy}$. It is revealed that in all irradiated samples with increasing volumetric filler content increase the dielectric characteristics of composites $P E+x$ vol\%. TIGaSe $_{2}$. Temperature variation of the dielectric parameters, after gamma irradiation are the result of occurring in the electron-ion and polarization at the interface of the matrix polymer with filler of $\mathrm{TlGaSe}_{2}$.
\end{abstract}

\section{Keywords}

Gamma Irradiation, Dielectric Properties, Composite Materials

\section{Introduction}

It is known that there are several ways for changing the properties of polymers. One of them is to add the low molecular weight disperse fillers to the volume of the polymer. This composite materials take an entirely new electro-physical, electret, strength, thermal, optical and other properties [1]-[5].

Usually, additives change supramolecular structure that largely determines physical, chemical and mechanical properties of polymers and composites based on them. This is due to the fact that when injecting small amount of fillers into polymers, the fillers act as artificial crystallization nuclei that leads to a change in the material properties. Thus, by changing the kind of fillers, the properties of polymer-based composite materials may be 
controlled. At present, there exists a rather large amount of works on investigation of fundamental properties of composites. However, there are no perfect models that explain the processes responding for change of electrophysical properties of polymers when introducing into them fillers, and also the action of ionizing radiations on these properties. In this connection, investigations of the effect of disperse fillers and also irradiation with $\gamma$-rays on electro-physical properties of polymers and composites based on them are very actual [6]-[8].

The purpose of work is to study the dielectric properties of $\gamma$-irradiated composites with semiconducting fillers as $\mathrm{PE}+\mathrm{x}$ vol\% $\mathrm{TlGaSe}_{2}$ dimensions $100 \mathrm{~nm}$.

\section{Experimental Technique}

Composite samples are obtained by mechanical mixing of $\mathrm{TlGaSe}_{2}$ powder with the PE powder in porcelain mortar. The mixing is continued until we have obtained a homogeneous mixture. The mixture is kept for some time at the melting temperature of the polymer under pressure of $5 \mathrm{MPa}$. In the same temperature by compacting the homogeneous mixture and the pressure slowly increases to $15 \mathrm{MPa}$. At this temperature, the sample is maintained for 5 minutes and then is quickly cooled in water. The sizes of the samples are: thickness is about 80 $120 \times 10^{-3} \mathrm{~mm}$, diameter of the obtained samples is $35 \mathrm{~mm}$. Provide reliable electric contact between the samples and electrodes made of stainless steel, the electrodes made of thin aluminum foil of thickness $7 \times 10^{-3} \mathrm{~mm}$ was pressed to both working surfaces of the sample.

The measurement of dielectric constant and dielectric loss PE $+x$ vol\% $\mathrm{TlGaSe}_{2}$ carried out in the range 296 $520 \mathrm{~K}$ with a linear rise in temperature at the rate of $2.5 \mathrm{~K} / \mathrm{min}$. Block diagram of the setup is shown in Figure 1. Measurement of $\varepsilon$ and $\operatorname{tg} \delta$ realized with alternating current frequency at $1 \mathrm{kHz}$. Sample (2) is kept between the two electrodes of the cell for measurement. Then the sample is heated in the cell via the heater (4) that was designed integrated in the laboratory with constant speed $2.5 \mathrm{~K} / \mathrm{min}$. The temperature of sample is registered by the thermocouple (3) by the system that attaches the heater 4 . Resistance of the sample is measured by the teraohmmeter (5) (E6-13A), while dielectric constant and dielectric loss measuring by the bridge E-20. The sample's temperature is measured by the temperature meter (6) (M-64). For the power supply of the heater used three-auto-regulated system (7).

\section{Results and Discussion}

The results of dielectric constant $(\varepsilon)$ and dielectric loss of composites $\mathrm{PE}+\mathrm{x}$ vol\% $\mathrm{TlGaSe}_{2}$ at different tem-

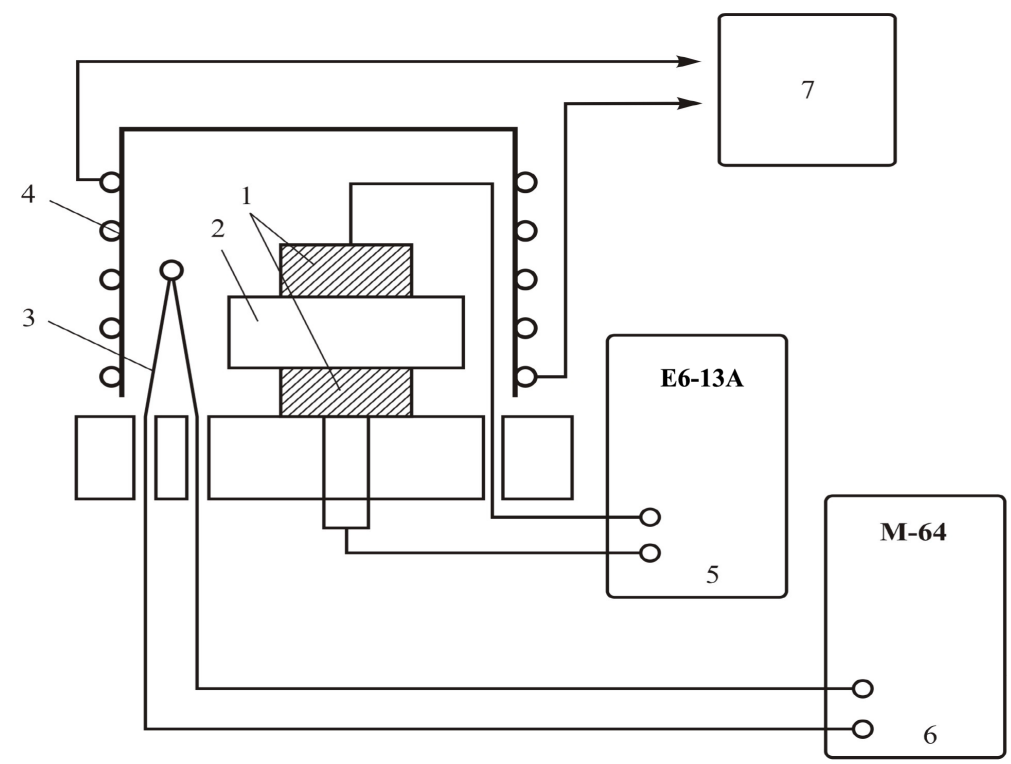

Figure 1. Block diagram of the apparatus for measuring temperature dependences of dielectric constant and dielectric losses: 1-measuring cell, 2-sample, 3-thermocouple, 4-heater, 5-immittance meter, 6-termometer, 7-three-autoregulated system. 
peratures up to $\gamma$-radiations is shown in Figure 2. The investigations were carried out at temperature range 300 $450 \mathrm{~K}$ for the composites PE $+\mathrm{x}$ vol\% $\mathrm{TlGaSe}_{2}$, where $\mathrm{x}=0$; 3; 5; 7 and $10 . \mathrm{TlGaSe}_{2}$. As is evident in Figure 2. in dependences $\varepsilon(\mathrm{T})$ and $\operatorname{tg} \delta(\mathrm{T})$ at temperatures 320 - $326 \mathrm{~K}$ there appears one low temperature maximum. With increasing the content of the filler $\mathrm{TlGaSe}_{2}$ the values of $\varepsilon(\mathrm{T})$ and $\operatorname{tg} \delta(\mathrm{T})$ increase.

At room temperature the values of dielectric constant of the composites with fillers $x=0 ; 3 ; 5 ; 7$ and 10 vol\% $\mathrm{TlGaSe}_{2}$ is 2.35, 2.7, 3, 3.40 and 3.65, while at temperature $320 \mathrm{~K}, 2.35,3.1,3.55,4.15$ and 4.5, respectively. In particular, for the composite $3 \mathrm{vol} \% \mathrm{TlGaSe}_{2}$ with increasing the temperature from the room temperature to 320 $\mathrm{K}, \varepsilon(\mathrm{T})$ increases by $17 \%$ (curve 2), for the composite with $\mathrm{x}=5$ (curve 3 ) at the same temperature range $\varepsilon(\mathrm{T})$ increases by $18 \%$, for the composite with $x=7$ (curve 4) by $22 \%$, for the composite with $x=10$ (curve 5) by 23\%. For the compositions under investigation, with increase of the filler content there happens increase of the quantity of $\varepsilon(\mathrm{T})$ and $\operatorname{tg} \delta(\mathrm{T})$, in particular, for the composites with $\mathrm{x}=0 ; 3 ; 5 ; 7$ and $10 \mathrm{x}$ vol\% $\mathrm{TlGaSe}_{2}$ at room temperature $\operatorname{tg} \delta(\mathrm{T})$ becomes $0.013,0.027,0.043,0.070$ and 0.10 , while for $330 \mathrm{~K}-0.013,0.043,0.0730 .113$, 0.24 , respectively. With increasing the filler content at temperature $330 \mathrm{~K}$ the diffuse maximums are observed. With change of temperature from the room temperature to $330 \mathrm{~K}$, for the composite 3 vol\% $\mathrm{TlGaSe}_{2}$ the amplitude of $\operatorname{tg} \delta(\mathrm{T})$ increases for the composites with fillers 5; 7 and $10 \mathrm{vol} \% \mathrm{TlGaSe}_{2}$ the increase of $\operatorname{tg} \delta(\mathrm{T})$ at the indicated temperature range is $17 \%, 16 \%$ and $24 \%$ respectively. For this composites with increasing the filler content, the value of $\varepsilon(\mathrm{T})$ and $\tan \delta(\mathrm{T})$ in the entire investigated temperature range is increased.

The effect of $\gamma$-irradiations on dielectric properties of the composites $\mathrm{PE}+\mathrm{x}$ vol\% $\mathrm{TlGaSe}_{2}$ is investigated. The studies were carried out on the composites irradiated at 50, 100, $150 \mathrm{kGy}$. The results are given in Figure 3. Temperature dependence of dielectric constant of composites $\mathrm{PE}+\mathrm{x}$ vol\% $\mathrm{TlGaSe}_{2}$, irradiated at dose of 50 kGy is given in Figure 3(a). As it follows in Figure 3(a), with increasing the filler's content, on the whole of temperature range there happens increase of $\varepsilon$, and on the curves $\varepsilon(\mathrm{T})$ the maximums appear. However, in the irradiated samples the maximums are shifted to the area of higher temperatures ( 360 - $370 \mathrm{~K}$ ) and become weakly expressed. In the composites irradiated at dose of $50 \mathrm{kGy}$ dependencies of maximums in $\tan \delta(\mathrm{T})$ were not revealed, monotone decrease of $\tan \delta(\mathrm{T})$ (Figure 3(b)) are observed.

The results of investigations of temperature dependence of dielectric constant of composites PE $+\mathrm{x}$ vol\% $\mathrm{TlGaSe}_{2}$, irradiated at dose of $100 \mathrm{kGy}$ are given in Figure 3(c). As is seen from Figure 3(c), $\varepsilon$ increases due to increase in the filler content. In particular, at room temperature, $\varepsilon$ for the composites with admixtures $\mathrm{x}=3$; 5 ; ; and $10 \mathrm{vol} \% \mathrm{TIGaSe}_{2}$ is 3.6, 4, 4.4 and 4.66, respectively, and at temperature $360 \mathrm{~K}, \varepsilon$ of these composites was 3.87; 5.2; 5.87 and 7.47, respectively. Thus, in irradiated $100 \mathrm{kGy}$ composites, at low temperatures with increasing the temperature from the room temperature to $370 \mathrm{~K}, \varepsilon$ increases, and with a further increase in temperature it decreases. Dielectric losses of these irradiated composites typical for all samples increase to $380 \mathrm{~K}$, and at temperature range 380 - $450 \mathrm{~K}$ it decreases (Figure 3(d)). The results of investigations of temperature dependences of dielectric constant of composites PE $+x$ vol\% $\mathrm{TlGaSe}_{2}$ irradiated at dose $150 \mathrm{kGy}$ are given in Figure $3(\mathrm{e})$, from which it follows that in $\varepsilon(\mathrm{T})$ dependence with the exception of pure polyethylene for all irradiated samples, with increasing temperature at wide range, dielectric constant increases. With increasing the filler content, the appropriate maximums of composites shift to the area of higher temperatures. Temperature dependence
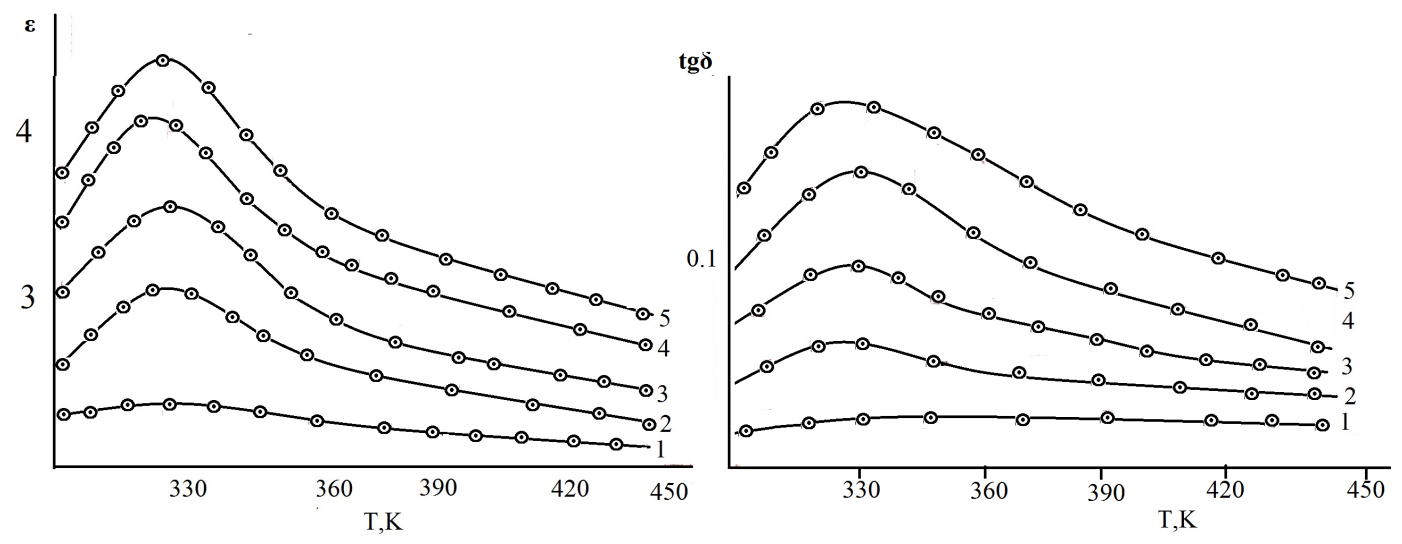

Figure 2. Temperature dependences of dielectric constant $(\varepsilon)$ and dielectric loss of composites $\mathrm{PE}+\mathrm{x}$ vol\% $\mathrm{TlGaSe}_{2}$, where $1-\mathrm{x}=0 ; 2-\mathrm{x}=3 ; 3-\mathrm{x}=5 ; 4-\mathrm{x}=7 ; 5-\mathrm{x}=10$. 

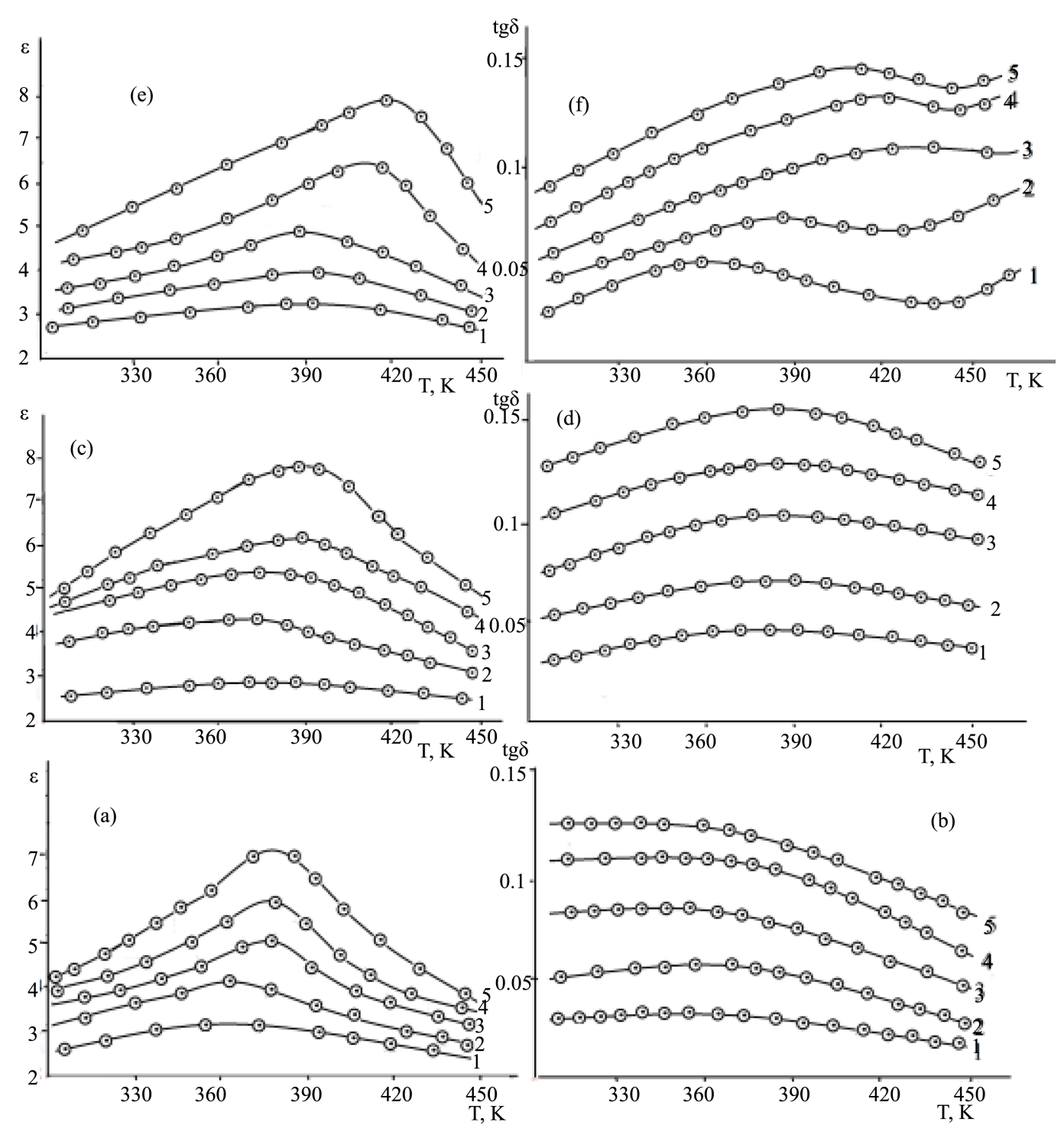

Figure 3. Temperature dependences of dielectic constant $(\varepsilon)$ and dielectric loss of composites PE $+\mathrm{x}$ vol\% $\mathrm{TlGaSe}_{2}$, under irradiated $50 \mathrm{kGy}$ (a) (b); $100 \mathrm{kGy}$ (c) (d); and $150 \mathrm{kGy}$ (e) (f) where 1-x = 0; 2-x = 3; 3-x = $5 ; 4-\mathrm{x}=7 ; 5-\mathrm{x}=10$.

of dielectric loss of composites radiated at the dose $150 \mathrm{kGy}$ is given in Figure 3(f). As it follows from Figure $3(\mathrm{f})$, the temperature dependence $\operatorname{tg}(\mathrm{T})$ of composites, irradiated at dose of $150 \mathrm{kGy}$ is relatively complicated, i.e. at lower temperatures $\tan \delta$ increases, at the certain interval it decreases, and at $420 \mathrm{~K}$ increases. Note that for the composites irradiated by $\gamma$-rays at dose of $150 \mathrm{kGy}$ the value of $\operatorname{tg} \delta$ increases due to increase of the filler content.

Analysis of the results of investigation of dielectric properties of irradiated composites $\mathrm{PE}+\mathrm{x} \mathrm{vol \%} \mathrm{TlGaSe}_{2}$ shows that on the temperature dependence $\varepsilon(\mathrm{T})$ before and after irradiation one single maximum is observed. Apparently, appearance of this maximum in connected with participation in polarization process deeper traps emerging after $\gamma$-radiation.

Effect of $\gamma$-radiation on composites $\mathrm{PE}+\mathrm{x}$ vol\% $\mathrm{TlGaSe}_{2}$ reduces to significant alternation in the dependence $\varepsilon(\mathrm{T})$ and $\tan \delta$ (Figure 2). So, after $\gamma$-radiation of composites in the interval 50 - $150 \mathrm{kGy}$, at temperature dependences $\varepsilon(\mathrm{T})$ one distinct maximum is observed. With increasing the dose of $\gamma$-radiation, the maximums in $\varepsilon(\mathrm{T})$ dependences shift to area of higher temperatures. Probably, appearance of maximum is connected with participation of deeper traps in the polarization process, and shift of the maximums is the result of change of the character of interphase boundary layer parameters after irradiation effect. 
Analysis of dependences $\tan \delta$ before and after $\gamma$-irradiations (Figure 2, Figure 3) shows that effect of $\gamma$-irradiation on the composites $\mathrm{PE}+\mathrm{x}$ vol\% $\mathrm{TlGaSe}_{2}$ reduces to significant change of dielectric losses. It is seen from $\tan \delta$ dependences that at lower doses (50 kGy) of radiation, the observed decrease of $\tan \delta$ is connected with the cross-linking processes that occur both in polymer matrix and in interphase layer of the polymer with $\mathrm{TlGaSe}_{2}$ filler. In the samples radiated at doses of $100 \mathrm{kGy}$, the observed relative stabilization of the value of $\tan \delta$ is the result of balancing of cross linking and destruction processes. In the samples irradiated with dose of $150 \mathrm{kGy}$ the changes of $\tan \delta$ are observed. Apparently, this is connected with prevalence of destruction processes.

Thus, changes in the dielectric characteristics of the composites based on polyethylene with $\mathrm{TlGaSe}_{2}$ filler after $\gamma$-radiation is the result occurring in the electron-ion and polarization processes in the polymer matrix and the interface of the polymer with the $\mathrm{TlGaSe}_{2}$ filler. These processes manifest themselves in increasing the concentration of low-energy surface states with increasing the filler content and the appearance of deep traps after $\gamma$-irradiation.

\section{Conclusion}

In this paper, we studied the effect of different doses of $\gamma$-irradiation on composites $\mathrm{PE}+\mathrm{x}$ vol\% $\mathrm{TlGaSe}_{2}$. The temperature dependence of the dielectric constant and dielectric loss of composites revealed that by changing the temperature and fillers content and the radiation dose could be obtained composite material with desired dielectric parameters

\section{References}

[1] Yabmekov, M.Y. and Gelman, A.B. (2011) Electret Properties of Polypropylene-Based Composite Materials. International Scientific Mechanical Conference, 14-17 November 2011, 78-80. (In Russian)

[2] Gojayev, E.M., Maherramov, A.M., Zeynalovsh, A., Osmanova, S.S. and Allahyarov, E.A. (2010) Coronoelectrets Based on High Density Polyethylene Composites with Semiconductor Filler TlGaSe $e_{2}$. Electronnaya Obrabotka Materialov, 46, 91-96. (In Russian)

[3] Mamedov, G.A., Gojayev, E.M., Magerramov, A.M. and Zeynalovsh, A. (2011) Investigation the Microrelyef of Surface by Atomic Force Microscop and Dielectric Properties of the Composition High Density Polyethylene with Additives TlGaSe 2 . Electronnaya Obrabotka Materialov, 47, 94-98.

[4] Radwan, R.M., Aly, S.S. and El Aal, S.A. (2008) Preparation, Characterization and Effect of Electron Beam Irradiation on the Structure and Dielectric Properties of $\mathrm{BatiO}_{3} / \mathrm{PVDF}$ Composite Films. Journal of Radiation Research and Applied Sciences, 11, 9-16.

[5] Shevchenko, V.G. (2010) Fundamentals of Physics of Polymer Composite Materials: Textbook/M. Moscow State University of M.V. Lomonosov, Moscow, 99. (In Russian)

[6] Maharramov, A.M., Quliyev, M.M. and Ismayilova, R.S. (2012) The Effect of Gamma-Irradiation on the Dielectric Behavior in Polypropylene-CdS/ZnS Composites Section II. Radiation Physics of Condensed Matter International Conference on Nuclear Science and Its Application, Samarkand, 25-28 September 2012, 192-194.

[7] Gafurov, U. and Fazilova, Z. (2007) Influence of Gamma-Irradiation on Dielectric Properties of Recycled Polyethylene Composites. MRS Proceedings, 1038, 61-69.

[8] Maharramov, A.M. (2001) Structural and Radiation Modification of Electret and Piezoelectret Properties of Polymer Composites. Baku, Elm, 327 p. 